\title{
Phenazine-1-Carboxylic Acid Production by Pseudomonas fluorescens LBUM636 Alters Phytophthora infestans Growth and Late Blight Development
}

\author{
Christopher K. Morrison, Tanya Arseneault, Amy Novinscak, and Martin Filion
}

Department of Biology, Université de Moncton, 18 Antonine-Maillet Ave., Moncton, NB, E1A 3E9 Canada. Accepted for publication 3 November 2016.

\begin{abstract}
Phytophthora infestans causes late blight of potato, one of the most devastating diseases affecting potato production. Alternative approaches for controlling late blight are being increasingly sought due to increasing environmental concerns over the use of chemical pesticides and the increasing resistance of $P$. infestans to fungicides. Our research group has isolated a new strain of Pseudomonas fluorescens (LBUM636) of biocontrol interest producing the antibiotic phenazine-1-carboxylic acid (PCA). Wildtype LBUM636 was shown to significantly inhibit the growth of Phytophthora infestans in in vitro confrontational assays whereas its isogenic mutant ( $p h z C-$; not producing PCA) only slightly altered the pathogen's growth. Wild-type LBUM636 but not the $p h z C$ - mutant also completely repressed

disease symptom development on tubers. A pot experiment revealed that wildtype LBUM636 can significantly reduce $P$. infestans populations in the rhizosphere and in the roots of potato plants, as well as reduce in planta disease symptoms due to PCA production. The expression of eight common plant defense-related genes (ChtA, PR-1b, PR-2, PR-5, LOX, $P I N 2, P A L-2$, and $E R F 3$ ) was quantified in tubers, roots, and leaves by reverse-transcription quantitative polymerase chain reaction and revealed that the biocontrol observed was not associated with the induction of a plant defense response by LBUM636. Instead, a direct interaction between $P$. infestans and LBUM636 is required and PCA production appears to be a key factor for LBUM636's biocontrol ability.
\end{abstract}

Late blight is one of the most important diseases affecting potato and is caused by the oomycete Phytophthora infestans (Haverkort et al. 2008). Resistance to pesticides, including mefenoxam, one of the fungicides most commonly used to control late blight, has been seen in North America and Europe following the migration of resistant $P$. infestans strains (Goodwin et al. 1996, 1998). Although, recently, the most dominant clonal lineages of $P$. infestans found in the northeastern United States and Canada have been described as sensitive to mefenoxam, some resistant strains are still being detected year after year and may cause a potential threat to potato culture in the future (Danies et al. 2013; Fry et al. 2015; Saville et al. 2015). With this resistance reservoir and the general public's aversion to the use of chemical pesticides, biocontrol is becoming an interesting way forward in managing this disease.

Biocontrol is a natural mechanism through which beneficial bacteria, often inhabiting the rhizosphere of plants, can reduce disease symptoms by using two main mechanisms: (i) direct interactions through competition with the pathogen or through the production of antibiotics (Compant et al. 2005) or (ii) indirect interactions through the activation of the plant's defense mechanisms leading to up- or downregulation of certain genes involved in the production of plant metabolites which are antagonistic toward the pathogen or that help protect the plant's cells from infection (Bakker et al. 2007; Yan et al. 2002).

Many Pseudomonas spp. have been identified as biocontrol agents, with strains capable of protecting plants from a wide variety of bacterial, fungal, and oomycete pathogens. Pseudomonas spp. can protect plants from bacterial pathogens such as potato common scab, caused by Streptomyces scabies (Arseneault et al. 2013); from

Corresponding author: M. Filon; E-mail address: martin.filion@umoncton.ca

*The $\boldsymbol{e}$-Xtra logo stands for "electronic extra" and indicates that three supplementary figures are published online.

(c) 2017 The American Phytopathological Society fungal pathogens such as Fusarium wilt on radish, caused by Fusarium oxysporum (de Boer et al. 1999), and tomato root rot, caused by $F$. oxysporum f. sp. racidis-lycopersici (Chin-A-Woeng et al. 1998); and even from oomycetes such as Pythium ultimum, causing damping-off in cotton (Loper 1988), just to name a few. The protection conferred by these Pseudomonas spp., thus far, has been mainly attributed to the production of antibiotics, which are vital in many strains' ability to effectively suppress diseases. A prime example of this is the production of the antibiotic phenazine-1carboxylic acid (PCA), which has been associated with the ability of Pseudomonas fluorescens 2-79 and P. chlororaphis 30-84 to control the take-all disease of wheat caused by Gaeumannomyces graminis var. tritici (Mazzola et al. 1995; Thomashow and Weller 1988).

Many studies to date have identified and characterized biocontrol agents that can protect potato plants from late blight (Axel et al. 2012). However, thus far, only few studies have been performed to identify and characterize Pseudomonas spp. that are capable of controlling Phytophthora infestans causing late blight of potato, and most of these have been limited to the use of a single or few assays, mostly performed in highly controlled environments such as detached-leaf or leaf disk assays (Daayf et al. 2003; De Vrieze et al. 2015; Guyer et al. 2015; Hultberg et al. 2010), in vitro confrontational assays (Daayf et al. 2003; de Souza et al. 2003; De Vrieze et al. 2015; Guyer et al. 2015; Hunziker et al. 2015; Van Der Voort et al. 2015), in vitro plantlet assays (Zakharchenko et al. 2011), potato tuber assays (Slininger et al. 2007), and in planta assays using mainly artificial substrates (Daayf et al. 2003; Hyo-Jeong et al. 2006). One of the most comprehensive of these studies (Daayf et al. 2003) tested 43 bacterial strains, including multiple strains of Pseudomonas spp., for their ability to protect potato from $P$. infestans. They identified Pseudomonas spp. displaying various inhibitory effects on $P$. infestans in in vitro confrontational assays, on detached potato leaf assays, and in whole plants grown in a growth chamber (Daayf et al. 2003) but did not specifically identify the biocontrol mechanisms involved. Although these studies clearly confirm that Pseudomonas spp. show great potential as biocontrol 
agents against late blight, the artificial conditions under which most of these studies were performed and the lack of understanding of the biocontrol mechanisms involved don't allow any conclusions to be made about the effectiveness of these strains at combatting late blight in the field.

In this study, we determined that a new strain of Pseudomonas fluorescens, LBUM636, isolated from a field in Bouctouche, Canada, and producing the antibiotic PCA, shows strong antagonistic activity against Phytophthora infestans and good biocontrol potential against late blight of potato. In order to provide a good overview of LBUM636's ability to control late blight under different conditions, as well as to gain as much information as possible on the potential biocontrol mechanisms involved, three different types of assays were performed: in vitro confrontational assays, tuber borehole assays, and in planta assays performed using agricultural soil to better simulate field conditions. Furthermore, to specifically assess the contribution of PCA production by LBUM636 to the biocontrol effects observed, an isogenic mutant of LBUM636 incapable of producing PCA $(p h z C-)$ was developed and used in parallel with wild-type LBUM636 in all experiments.

\section{MATERIALS AND METHODS}

Bacterial strains, growth conditions, and preparation of inocula. Pseudomonas fluorescens strain LBUM636, a PCA producer (Morrison et al. 2016), was isolated using standard microbiological procedures from the rhizosphere of a strawberry plant in Bouctouche, NB, Canada. An isogenic mutant incapable of producing PCA, LBUM636 phzC-, was developed and validated using the same procedure as previously described by St-Onge et al. (2011), in which the $p h z C$ gene was disrupted using the suicide plasmid pKNOCK-Gmr. Bacterial strains were grown in tryptic soy broth (BD Biosciences, Franklin, NJ) at $25^{\circ} \mathrm{C}$ for $48 \mathrm{~h}$. Cultures were diluted to $5 \times 10^{8} \mathrm{CFU} / \mathrm{ml}$ for all experiments. Populations were estimated using spectrophotometer readings $(\lambda=600 \mathrm{~nm})$ and previously determined standard curves.

Pathogen strain, growth conditions, and preparation of inoculum. Phytophthora infestans (strain US-8) was grown on $10 \%$ unclarified $\mathrm{V} 8$ agar at $20^{\circ} \mathrm{C}$ for general propagation and at $15^{\circ} \mathrm{C}$ for the production of sporangia. Sporangial inoculum was prepared following 16 days of growth by adding $10 \mathrm{ml}$ of sterilized tap water $\left(4^{\circ} \mathrm{C}\right)$ per petri dish and scrapping the surface of the mycelium with an L-shaped spreader. Sporangia concentration was determined using a hemocytometer and the solution was diluted using sterilized tap water to obtain a final concentration of $2 \times 10^{4}$ sporangia/ml. The sporangial inoculum was kept at $4{ }^{\circ} \mathrm{C}$ for $2 \mathrm{~h}$ until zoospore release was observed under a microscope, and then used immediately.

In vitro confrontational assays. In vitro confrontational assays were performed in petri dishes containing three different growth media: $10 \%$ unclarified V8 agar, rye agar, and potato dextrose agar (PDA) (BD Biosciences). A P. infestans plug (5 mm in diameter) obtained from a fresh culture was placed in the center of each petri dish. A bacterial culture treatment (LBUM636 or LBUM636 phz C-) was then applied in four 10- $\mu$ l aliquots at equidistant extremities of the petri dishes. The treatments were (i) control (P. infestans only), (ii) $P$. infestans + LBUM636, and (iii) $P$. infestans + LBUM636 phzC-. Incubation was performed at $20^{\circ} \mathrm{C}$ and was ended for each growth medium when the growth of the pathogen in the control treatment reached the extremities of the petri dishes. The experiment was performed using four replications per treatment per type of media, and was replicated entirely $(n=8)$. Inhibition zone values were obtained by measuring the shortest distance between the edges of the pathogen's growth area and the edges of each bacterial colony (four measurements) and averaged out for each unit (petri dish).

Potato tuber experiment. A potato tuber experiment was performed by boring holes into tubers ('Shepody' potato). Holes were made $1.5 \mathrm{~cm}$ deep using a 3 -mm cork borer. Two different assays were performed, one where tubers had a single central hole, and a second where two holes were done on the same side of the tuber and $10 \mathrm{~cm}$ apart. Pathogen sporangial inoculum $(20 \mu \mathrm{l})$ was added first to all treatments requiring it and allowed to set for $30 \mathrm{~min}$. Bacterial solution $(20 \mu \mathrm{l})$ was then added to all treatments requiring it. For the single-hole assay, the bacterial solution was added to the same hole as the sporangial inoculum whereas, for the two-hole assay, the sporangial inoculum and the bacterial solution were added to different holes. Sterile tap water $(20$ or $40 \mu \mathrm{l})$ was added in lieu of sporangia or bacterial solutions in treatments not receiving one or both. The treatments were (i) control (no inoculation), (ii) LBUM636, (iii) LBUM636 phzC-, (iv) $P$. infestans, (v) P. infestans + LBUM636, and (vi) P. infestans + LBUM636 phzC-. The experiment was performed using four replications per treatment, and was replicated entirely $(n=8)$. Tubers were incubated with no light at $15^{\circ} \mathrm{C}$ for 2 weeks. Tubers were then cut in half and photographed.

For tuber RNA extractions, a cork borer was used to sample each tuber at five equidistant points on the outer edge, without sampling near the inoculation holes. The five samples were combined, then ground using a mortar and pestle, and $70 \mathrm{mg}$ of the tissue was weighed and immediately placed in RNAzol RT extraction buffer (Sigma-Aldrich, Oakville, ON, Canada), frozen in liquid nitrogen, and stored at $-80^{\circ} \mathrm{C}$ until extractions were performed.

Growth chamber experiment. Agricultural soil (sandy loam, $\mathrm{pH}$ 6.7) was obtained from the Agriculture and Agri-Food Canada S. H. J. Michaud Research Farm (Bouctouche, NB, Canada) and refrigerated until use. Soil was mixed with sand (three parts soil to one part sand) and $1.1 \mathrm{~kg}$ was added to each 6-in $(15 \mathrm{~cm})$. planting pot. Certified seed tubers (Shepody potato) were stored at ambient temperature until sufficiently sprouted, then cut so as to have at least one sprout per piece and placed at $15^{\circ} \mathrm{C}$ without light for 3 days to heal. Tuber pieces were planted at a depth of approximately $5 \mathrm{~cm}$. Addition of inocula was done once at planting by first adding $10 \mathrm{ml}$ of pathogen sporangia solution to all treatments requiring it and allowing it to set for $30 \mathrm{~min}$. Bacterial solution $(20 \mathrm{ml})$ was then added to all treatments requiring it. Sterile water $(10,20$, or $30 \mathrm{ml})$ was added in lieu of sporangia or bacterial solutions in treatments not receiving one or both. Solutions were added to cover the entire tuber and the surrounding soil before carefully burying the seed. The treatments were (i) control (no inoculation), (ii) LBUM636, (iii) LBUM636 phzC-, (iv) P. infestans, (v) P. infestans + LBUM636, and (vi) $P$. infestans + LBUM636 phz $C$ - . The experiment was performed using 18 replications per treatment, with three harvesting time points $(15,30$, and 45 days, 6 plants per time point, destructive sampling), and was replicated entirely ( $n=12$ plants at each time point). The pots were placed in a growth chamber (Conviron CMP5000 series; Controlled Environments, Winnipeg, MB, Canada) in a completely randomized design and plants were grown at a constant temperature of $18^{\circ} \mathrm{C}$, with $16 \mathrm{~h}$ of daylight and $85 \%$ humidity. Plants were watered daily or every other day as needed with 100 to $150 \mathrm{ml}$ of tap water. Fertilization was performed once the plants had broken soil and again 3 weeks later with an all-purpose 20-20-20 N:P:K water-soluble fertilizer. At each harvesting time point, rhizosphere soil was collected by first removing and discarding bulk soil from the roots, then shaking the roots to collect the closely adhering soil. The root system was then thoroughly washed and dried and total plant weight was measured. Leaves and roots were harvested separately to be used for DNA extractions (roots only) and RNA extractions (leaves and roots). Tissue samples were handled as quickly as possible, frozen in liquid nitrogen, and kept at $-80^{\circ} \mathrm{C}$ until use. Tuber production was not assessed because harvests were done too early to consistently obtain tubers.

Extraction and retrotranscription of tuber RNA. RNA extraction was performed (Chomczynski et al. 2010) using the tuber samples prepared as described earlier. The RNAzol RT buffer containing the tuber tissue was thawed, $0.4 \mathrm{ml}$ of RNase-free water was added, and the whole was vigorously vortexed for $15 \mathrm{~s}$. The solution was incubated at room temperature for $15 \mathrm{~min}$ and then 
centrifuged at $12,000 \times g$ for $5 \mathrm{~min}$ at $4^{\circ} \mathrm{C}$. The supernatant was transferred to a new tube and 4-bromoanisole was added to a final concentration of $0.5 \%$. The solution was mixed and incubated for $5 \mathrm{~min}$ before being centrifuged at $12,000 \times g$ for $5 \mathrm{~min}$ at $4^{\circ} \mathrm{C}$. The supernatant was transferred to a new tube and an on-column cleanup was performed using the Zymo Research Direct-zol RNA MiniPrep Plus (Cedarlane, Burlington, ON, Canada). RNA was quantified by spectrophotometry (NanoDrop Technologies, Wilmington, DE) and samples were diluted to $40 \mathrm{ng} / \mu \mathrm{l}$. Retrotranscription was performed using oligo-dT and the TaqMan Reverse Transcription Reagents Kit (Applied Biosystems, Foster City, CA) to obtain $100 \mu \mathrm{l}$ of cDNA solution, which was then diluted 1:2 prior to quantitative polymerase chain reaction (qPCR).

Extraction and retrotranscription of plant RNA. Leaf and root samples were ground in RNase-free mortars and pestles using liquid nitrogen. RNA extraction was performed using the RNeasy Plant Mini Kit (Qiagen, Mississauga, ON, Canada) following the manufacturer's instructions (using the RLT buffer) and the optional on-column DNase (Qiagen) was also performed. RNA was quantified by spectrophotometry (NanoDrop) and samples were diluted to $50 \mathrm{ng} / \mu \mathrm{l}$. Retrotranscription was performed as described previously for tuber RNA samples.

Extraction of root and soil DNA. DNA extractions from root samples were performed using the same ground tissue used in the extraction of plant RNA described above. The DNeasy Plant Mini Kit (Qiagen) was used according to the manufacturer's instructions. Soil samples were lyophilized and DNA extraction was performed using a previously described method (Griffiths et al. 2008). The resulting DNA solutions were diluted 1:2 before being used in qPCR analyses.

Relative expression of defense-related genes. cDNA samples obtained from both the tuber experiment (tuber tissues) and the growth-chamber experiment (leaf and root tissues) were submitted to qPCR analyses using a previously described procedure (Arseneault et al. 2014). Reverse-transcription (RT)-qPCR analyses were performed on a CFX Connect Real-Time PCR Detection System (Bio-Rad, Mississauga, ON, Canada). Eight previously described (Arseneault et al. 2014) plant defense-related genes were targeted: ChtA, PR-1, PR-2, PR-5, ERF3, LOX, PAL-2, and PIN2. The same two reference genes $(E F I-\alpha$ and $C y P)$ were used to normalize data and were similarly validated in our system. Data analyses and final results were obtained as previously described (Arseneault et al. 2014).

$P$. infestans populations in soil and root tissue. Populations of $P$. infestans in soil and root samples were estimated by qPCR by targeting $a v r 3 a$, a gene unique to this pathogen. The primers and the TaqMan probe used were described previously (Clément et al. 2013). Reactions $(20 \mu \mathrm{l})$ were performed using $10 \mu \mathrm{l}$ of iTaq Universal Probes Supermix (Bio-Rad) and $4.8 \mu \mathrm{l}$ of DNA. Primers and probes were set to a final concentration of $200 \mathrm{nM}$. Each reaction was performed in triplicate. Direct quantification of $P$. infestans in the soil and roots was achieved by including serial dilutions of a plasmid solution containing an insertion of the $a v r 3 a$ gene. A standard curve was generated for each plate and allowed conversion of cycle threshold values to a number of copies of arv $3 a$. Plasmid standards were developed as previously described (DeCoste et al. 2010).

Statistical analyses. All statistical analyses were performed using R, the open-source statistical software (ver. 3.2.4). To allow the analyses of multiple replications of the same experiment as a whole, mixed models were used when applicable to remove possible variation due to replication. Analyses of gene expression were performed using three-factor analyses of variance (where factors were time, presence or absence of pathogen, and presence or absence and type of Pseudomonas sp.). The data required log transformations to obtain normality. Analysis of the populations of $P$. infestans in root tissue was done using a two-factor analysis of variance (where factors were time and presence or absence and type of Pseudomonas sp.). No transformations of the data were required. Analyses of the populations of $P$. infestans in soil and of plant weight were performed using a simple analysis of variance (treatments as the single factor). No transformation was required on either data set to obtain normality. In vitro confrontational assays were analyzed using a two-factor analysis of variance (where factors were treatments and media). No transformations of data were necessary and no interaction was observed between the treatments; therefore, treatments were compared with one another for all types of media combined. TukeyKramer adjustments were used for all analyses to determine significance $(P<0.05)$.

\section{RESULTS}

In vitro confrontational assays. Confrontation with LBUM636 or LBUM636 phz C- significantly reduced $(P<0.001) P$. infestans growth when compared with control samples (Fig. 1). Analysis of

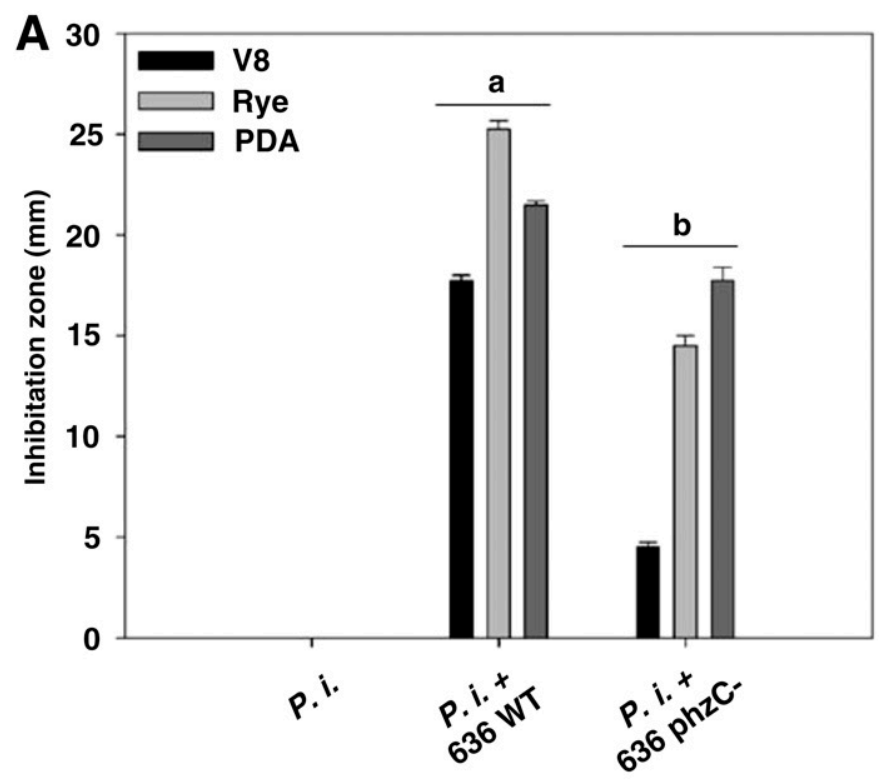

B

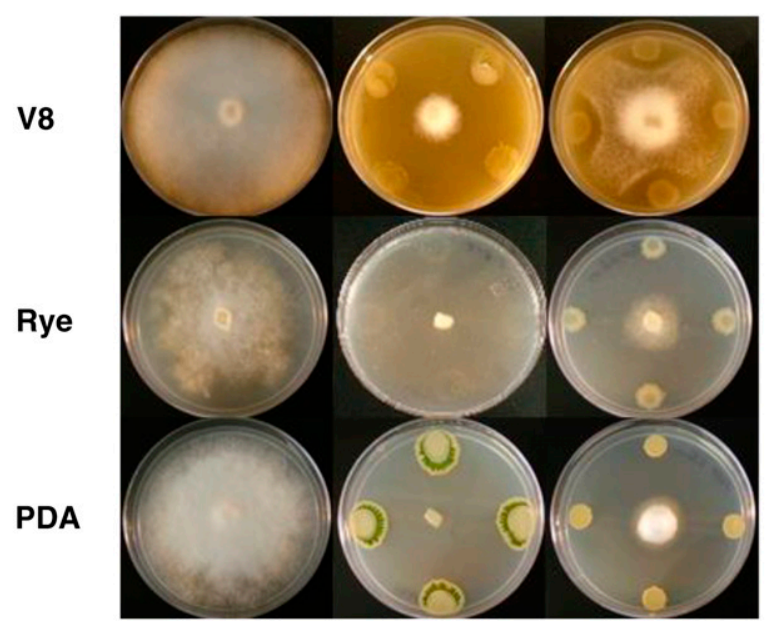

Fig. 1. A, Net average of the inhibition zones (in millimeters) and B, corresponding photos from in vitro confrontational assays between Phytophthora infestans (P.i.) and wild-type Pseudomonas fluorescens LBUM636 (636 WT) or $P$. fluorescens LBUM636 phzC- (636 phzC-), an isogenic mutant incapable of producing phenazine-1-carboxylic acid, on three different culture media: V8 agar (V8), rye agar (Rye), and potato dextrose agar (PDA). Inhibition zones were calculated (and photos taken) for each growth medium when the growth of the pathogen in the control treatment reached the extremities of the petri dishes. Values are presented as mean \pm standard error of the mean $(n=8)$. Treatments were compared using mixed analyses of variance. Error bars are standard error of the mean with media grouped, and significant differences according to a posteriori Tukey-Kramer honestly significant differences tests $(P<0.05)$ are presented using letters. 
the inhibition zones demonstrated that, although the mutant strain was capable of inhibiting the growth of the pathogen when compared with the control, production of PCA by LBUM636 led to a significantly higher inhibitory effect $(P<0.05)$, suggesting that PCA production by LBUM636 contributes significantly to this growth inhibition. Although the general effect was the same for all media used, the overall size of inhibition zones and the level of inhibition did change from one medium to another. The bacteria and the pathogen grew at different rates, with the bacterial colonies being different sizes on different media when the experiment was ended and measurements were taken.

Tuber experiment: Symptoms. The tuber experiment's results are presented separately for the single-hole assay (Fig. 2) and two-hole assay (Fig. 3). In both cases, no disease symptoms were observed in treatments that did not receive $P$. infestans (Figs. $2 \mathrm{~A}, \mathrm{~B}$, and $\mathrm{C}$ and $3 \mathrm{~A}, \mathrm{~B}$, and $\mathrm{C}$ ), whereas inoculation with P. infestans alone (Figs. 2D and 3D) shows classic symptoms of late blight. The coinoculation of LBUM636 phzC- with $P$. infestans (Figs. 2F and 3F) did not prevent symptoms from appearing in either type of assay. In the single-hole assay only, the coinoculation of LBUM636 with $P$. infestans (Fig. 2E) led to a complete absence of symptoms in all samples. This was not observed in the two-hole assay, where symptoms were similar to the P. infestans alone or the LBUM636 phz $C-+P$. infestans treatments (Fig. 3E).

Growth chamber experiment: Disease symptoms, plantgrowth-promoting activity, and $P$. infestans populations. Disease symptoms in the growth chamber experiment included smaller plant weights, darkening of roots, and desiccation of the seed tubers in plants that received the pathogen. Plants inoculated with the pathogen only were significantly smaller $(P<0.05)$ than control plants, while plants inoculated with LBUM636 or LBUM636 phzC- had significantly higher average weights than control plants $(P<0.005)$ (Fig. 4). LBUM636 also had a significantly $(P<0.05)$ higher plant-growth-promotion effect than LBUM636 phzC-. The coinoculation of either bacterial strain with the pathogen led to significantly higher average plant weights when compared with plants having only received the pathogen but there was no significant difference between plants coinoculated with either of the two bacterial strains.

Populations of $P$. infestans in the root tissues decreased over time, regardless of treatment (Fig. 5). Coinoculation with LBUM636 significantly reduced pathogen populations at all time points

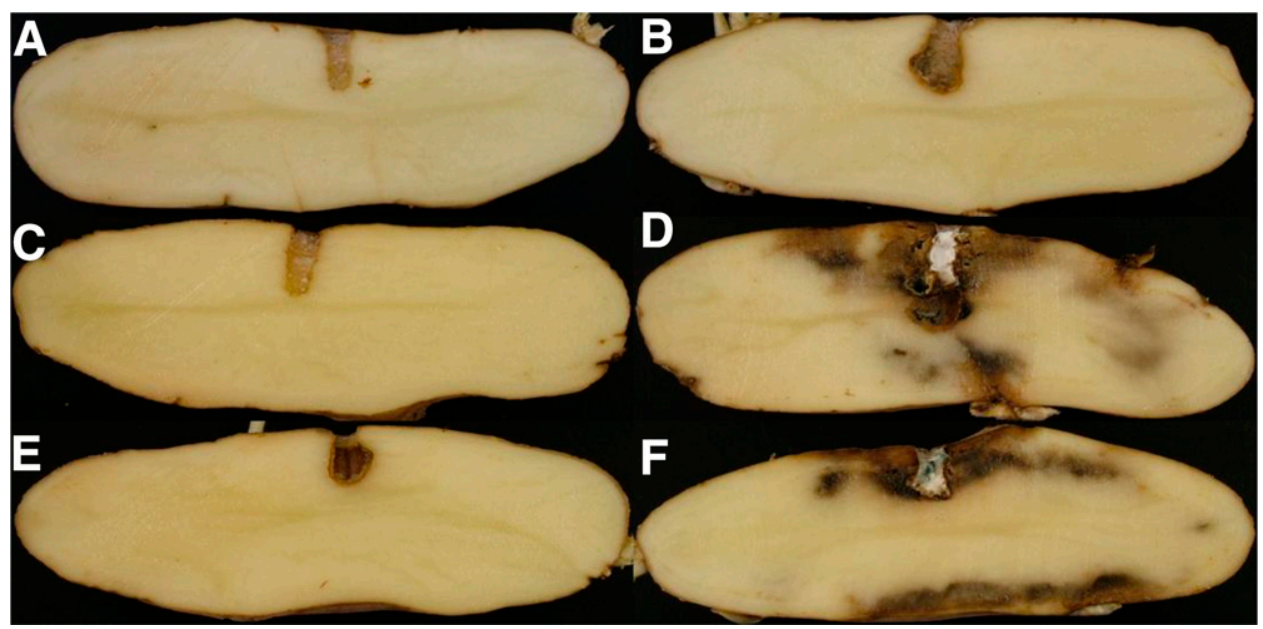

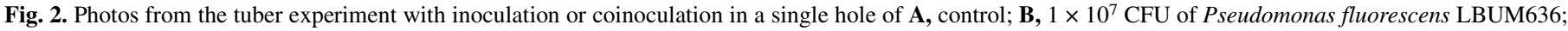

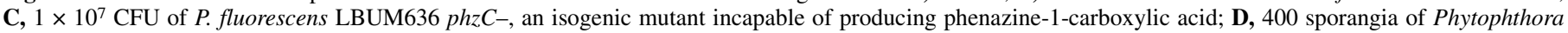

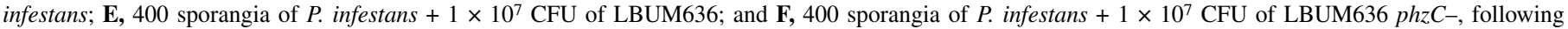
2 weeks of incubation.

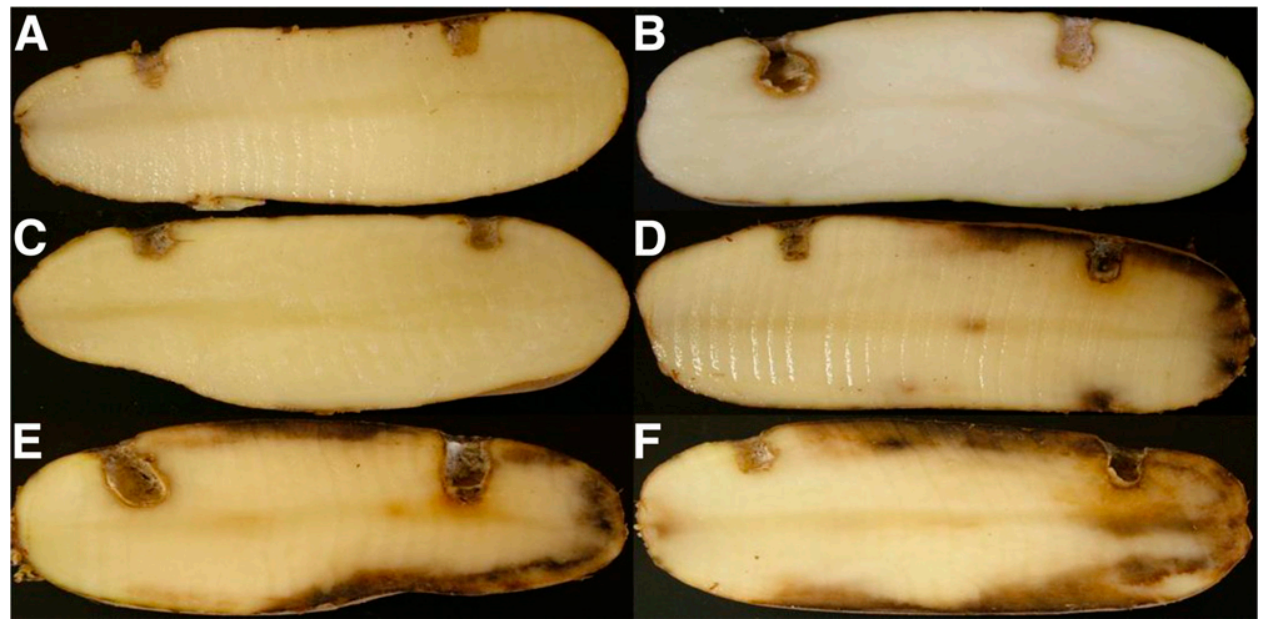

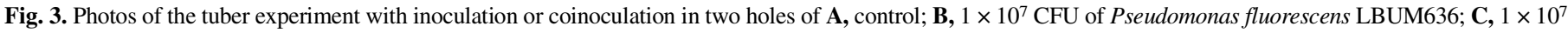

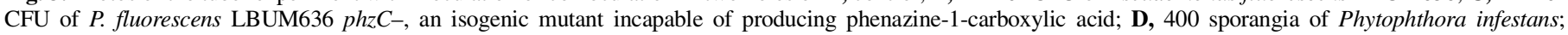

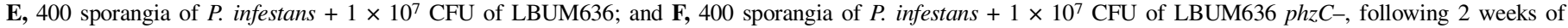
incubation. Inoculation was done in two holes, with $P$. infestans applied in the right hole and LBUM636 or LBUM636 phzC- applied in the left hole. 
$(P<0.005)$, whereas coinoculation with LBUM636 phz $C$ - only did so at days 15 and $45(P<0.05)$. In general, except at day 15 , coinoculation with LBUM636 led to significantly lower $(P<0.05)$ $P$. infestans populations than coinoculation with LBUM636 phz C-. Populations of $P$. infestans in the rhizosphere soil declined after day 15 and no detection was possible at days 30 and 45 . The coinoculation with either strain of bacteria significantly reduced $P$. infestans populations in the rhizosphere (Fig. 6) $(P<0.001)$ but PCA production by LBUM636 led to a significantly higher $(P<0.05)$ reduction than coinoculation with LBUM636 phzC-.

Relative expression of defense-related genes. The presence of the pathogen or LBUM636 or its isogenic mutant did not significantly up- or downregulate the expression of any of the plant defense gene tested. This is true for both the tuber experiment (Supplementary Fig. S1) and the growth-chamber experiment (Supplementary Figs. S2 and S3).

\section{DISCUSSION}

Our results have shown that LBUM636 is capable of inhibiting $P$. infestans growth under in vitro and in planta conditions mainly through PCA production, leading to biocontrol. The importance of PCA production by LBUM636 in this inhibition was confirmed by demonstrating that the growth of the pathogen was much less inhibited by an isogenic PCA-deficient mutant strain in the in vitro confrontational assays and in the pot experiment. In the tuber experiment, disease suppression was not observed on tubers in the presence of the mutant strain as it had been clearly observed in the presence of the wild-type PCA-producing strain.

The in vitro confrontational assay performed using $P$. infestans and LBUM636 (wild type and $p h z C$ - mutant) first confirmed the antagonistic effect of LBUM636 against the pathogen, mainly through PCA production. Similar results were obtained regardless of the growth medium used.

In the pot experiment, coinoculation of $P$. infestans with either LBUM636 or its PCA-deficient mutant significantly reduced pathogen populations in the rhizosphere soil and roots when compared

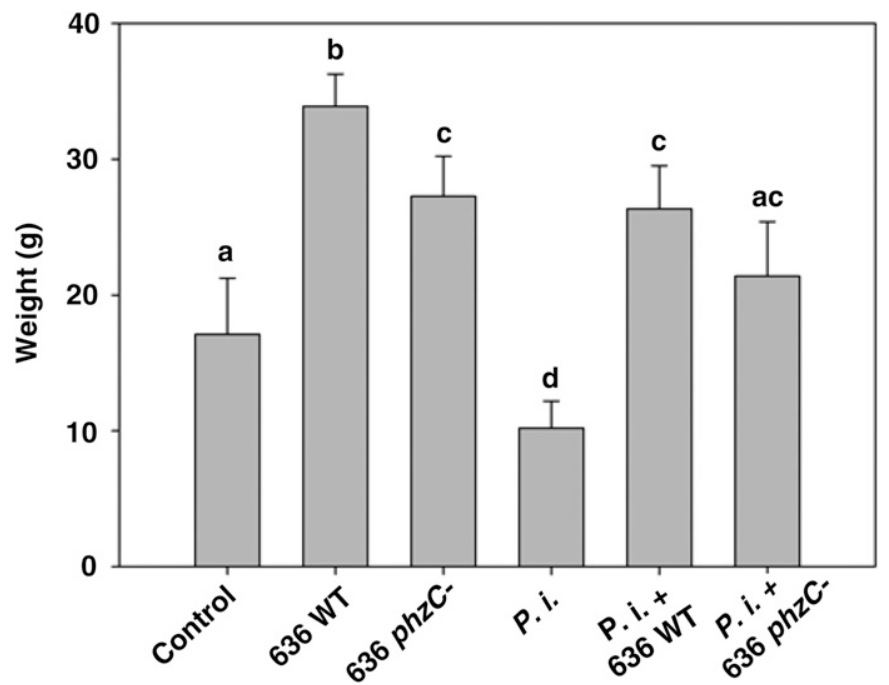

Fig. 4. Weight (combination of total foliar and root weight) at 45 days of potato plants cultivated in growth chambers. Treatments were control; Pseudomonas fluorescens LBUM636 (636 WT); P. fluorescens LBUM636 $p h z C-(636 p h z C-)$, an isogenic mutant incapable of producing phenazine-1carboxylic acid; Phytophthora infestans (P.i.), P.i. + $636 \mathrm{WT}$, and P.i. +636 $p h z C-$. Values are presented as mean \pm standard error of the mean $(n=12)$. Treatments were compared using mixed analyses of variance. Error bars are standard error of the mean and significant differences according to a posteriori Tukey-Kramer honestly significant differences tests $(P<0.05)$ are presented using letters. with plants that received only the pathogen (with one exception for the PCA-mutant strain at day 30 in the root tissues). Because an indirect interaction leading to biocontrol through the activation of the plant's defense mechanisms by LBUM636 was possible under these conditions, RT-qPCR assays were performed on a set of eight potato genes well known for their implication in disease resistance. The absence of a significant up- or downregulation of any of these defense-related genes in roots and leaves at different sampling dates strongly suggests that neither an induced systemic resistance (ISR) nor a systemic acquired resistance (SAR) response was likely involved in the biocontrol observed. However, it was surprising to detect the absence of an SAR response in potato plants when the pathogen was inoculated alone. It is well established that pathogens are capable of inducing an SAR response in numerous plants, which can be confirmed by the differential expression of genes involved in the production of pathogenesis-related (PR) proteins (Ryals et al. 1996). However, under our experimental conditions, there was no significant difference in the expression of the $P R-1, P R-2, P R-5$, or CHTA genes, which are generally associated with an SAR response.

Similarly, no significant changes were detected in the expression profiles of the defense genes in the tuber experiment when the pathogen was either inoculated alone or coinoculated with LBUM636 (wild-type and PCA-mutant strains). Interestingly, in this experiment, PCA production by wild-type LBUM636 was clearly identified as the main biocontrol determinant because a complete absence of disease symptoms was observed when LBUM636 was coinoculated with the pathogen in the same tuber hole, whereas no disease reduction was observed when the PCA-deficient mutant was coinoculated with the pathogen. A direct contact between both organisms was required for biocontrol to occur because no disease symptom reduction was observed when wild-type LBUM636 was inoculated in one hole and the pathogen in another hole on the same tuber. This suggests that either (i) PCA is wholly responsible for the repression of disease symptoms or (ii) PCA produced by LBUM636 is a significant contributor of this organism's ability to inhabit its environment and

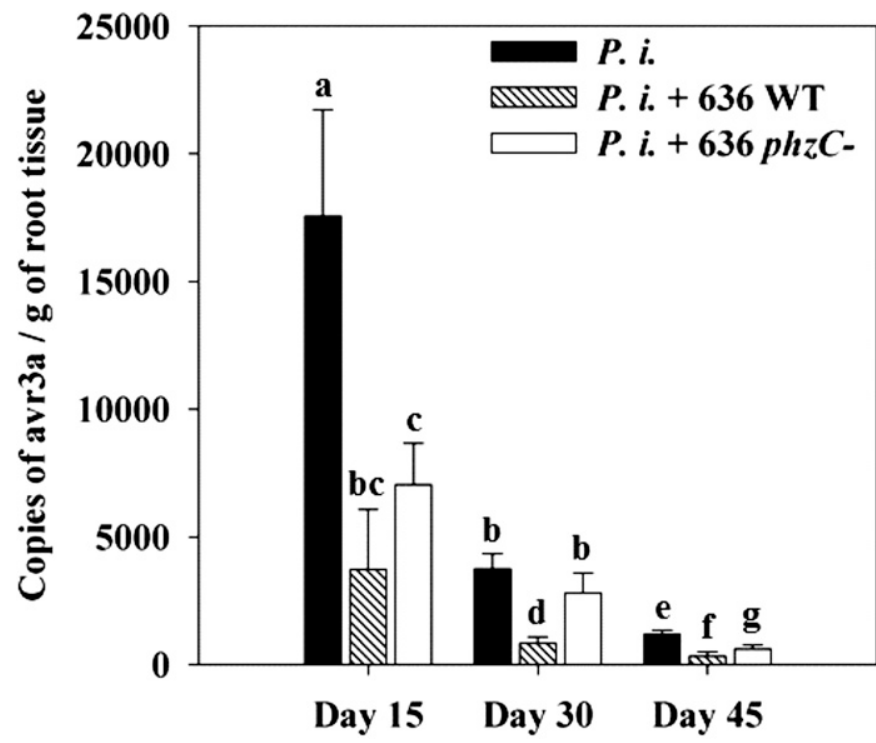

Fig. 5. Populations of Phytophthora infestans (P.i.) determined using quantitative polymerase chain reaction quantification of the $a v r 3 a$ gene in the roots of potato plants cultivated in growth chambers. Treatments were P.i., either inoculated alone or in combination with wild-type Pseudomonas fluorescens LBUM636 (636 WT) or $P$. fluorescens LBUM636 phzC- (636 phzC-), an isogenic mutant incapable of producing phenazine-1-carboxylic acid. Treatments that were not inoculated with P.i. are not shown. Values are presented as mean \pm standard error of the mean $(n=12)$. Treatments were compared using mixed analyses of variance. Error bars are standard error of the mean and significant differences according to a posteriori Tukey-Kramer honestly significant differences tests $(P<0.05)$ are presented using letters. 
compete with $P$. infestans for nutrients or ecological niches. Phenazine production has previously been shown to affect Pseudomonas spp. strains' competence as biocontrol agents. For example, the production of phenazines by Pseudomonas fluorescens 2-79 and P. aureofaciens 30-84 was shown to contribute to their ability to compete with the resident microflora and persist in soil and in the rhizosphere of wheat (Mazzola et al. 1992). The formation of biofilm has been shown to be important for the persistence of some bacteria in the soil and on roots, and phenazine production has also been linked to an increase in biofilm formation for some Pseudomonas spp., such as $P$. chlororaphis PA23 (Selin et al. 2010) and P. chlororaphis strain 30-84 (Maddula et al. 2006). Finally, P. fluorescens 2-79's ability to control take-all disease of wheat is significantly higher than its PCA-deficient mutant (Thomashow and Weller 1988), which exemplifies the importance of PCA production in some strains' biocontrol ability. In any case, the need for direct contact between the two organisms for LBUM636 to repress disease symptoms in the tuber experiment suggests that diffusion of PCA through the tuber did not occur at sufficient levels over the $10-\mathrm{cm}$ distance between the organisms inoculated in two different holes. This is in contrast to the in vitro experiment where diffusion of PCA in the medium allowed for inhibition of Phytophthora infestans growth over some distance.

$P$. infestans efficiently colonized the roots of the potato plants in the pot experiment. Although P. infestans was no longer detectable in the soil at the last two harvests (days 30 and 45), its populations in the root tissue remained detectable over time. Although we can reasonably assume that LBUM636 (wild type or $p h z C-$ ) and $P$. infestans had direct contact in the soil and on the surface of plant parts, it is less certain that LBUM636 had direct contact with the populations of $P$. infestans in the root tissue itself. Many Pseudomonas spp. have demonstrated their ability to colonize the root system of numerous plants as endophytes and their colonization of the plant can sometimes contribute significantly to their ability to promote the

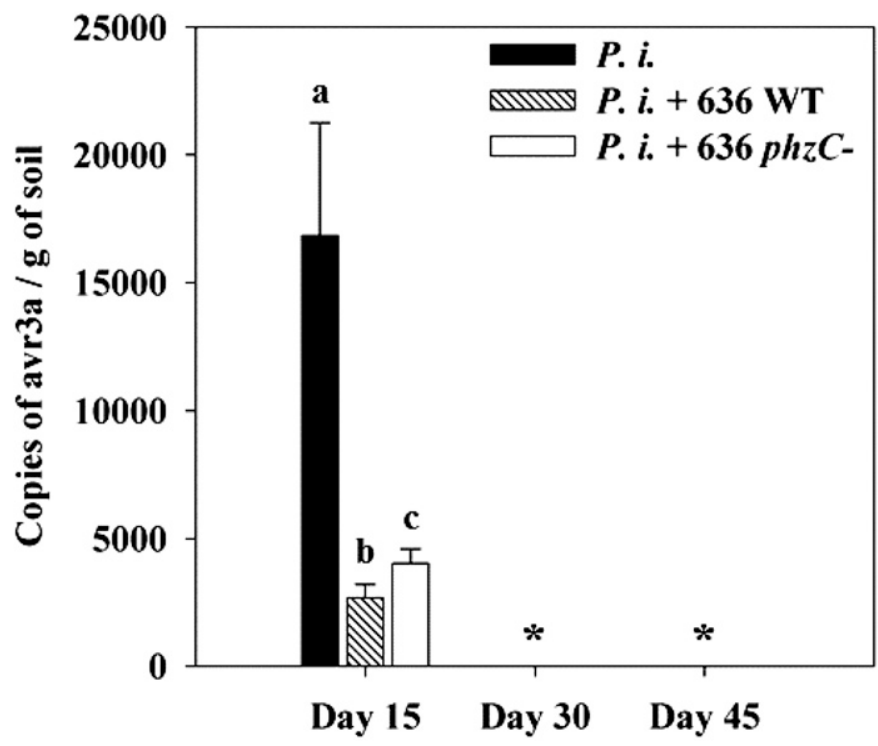

Fig. 6. Populations of Phytophthora infestans (P.i.) determined using quantitative polymerase chain reaction quantification of the $a v r 3 a$ gene in the rhizosphere of potato plants cultivated in growth chambers. Treatments were P.i., either inoculated alone or in combination with wild-type Pseudomonas fluorescens LBUM636 (636 WT) or P. fluorescens LBUM636 phzC- (636 phzC-), an isogenic mutant incapable of producing phenazine-1-carboxylic acid. Treatments that were not inoculated with P.i. are not shown. Asterisks (*) indicate that no detection of the avr3a gene was observed at day 30 and day 45. Values are presented as mean \pm standard error of the mean $(n=12)$. Treatments were compared using mixed analyses of variance. Error bars are standard error of the mean and significant differences according to a posteriori Tukey-Kramer honestly significant differences tests $(P<0.05)$ are presented using letters. plant's growth and to protect the plant from diseases. Pseudomonas fluorescens FPT9601-T5 is an endophytic plant growth promoter of Arabidopsis thaliana (Wang et al. 2005). P. fluorescens strain WCS417r colonizes the roots of tomato, a solanaceae-like potato (Duijff et al. 1997), and P. putida strain P9 is an endophyte in potato and causes cultivar-dependent suppression of Phytophthora infestans (Andreote et al. 2009). In this study, the endophytic colonization potential of LBUM636 was not evaluated but this potential capability should be determined in future studies.

The pot experiment also demonstrated that LBUM636 is a plant growth promoter of potato. At 45 days, plants that were inoculated with either wild-type LBUM636 or its PCA-deficient mutant were significantly heavier than control plants. Although plants inoculated with wild-type LBUM636 were significantly heavier that the ones inoculated with the PCA-deficient mutant, PCA cannot by identified as the main driver of this growth promotion because the difference observed was subtle compared with the difference observed between the control plants and the ones inoculated with either LBUM636 strain. When plants were inoculated with the pathogen alone, plant weight was significantly reduced compared with control plants, a consequence of $P$. infestans colonization and disease development. Among plants that were coinoculated with the pathogen and LBUM636 (wild type or PCA-deficient mutant), a similar increase in plant weight was observed as when LBUM636 was inoculated alone, counterbalancing plant weight reduction caused by the infection by $P$. infestans. Other Pseudomonas spp. have also previously been described as plant-growth promoting bacteria (PGPR) of potato (Arseneault et al. 2013; Kloepper et al. 1980).

This study demonstrated that LBUM636 is antagonistic toward P. infestans and does contribute to the control of late blight of potato. Production of PCA was identified as the key determinant of its biocontrol capability. LBUM636 could also be considered a plant growth promoter of potato, another characteristic that makes it a prime candidate to become an efficient inoculant to be used under natural field settings. Field tests represent the next step to determine LBUM636's performance under agricultural settings. LBUM636's ability to control late blight will also need to be assessed on other clonal lineages of $P$. infestans, especially those which have been identified as the most common in North America in recent years, because its effectiveness against different strains could potentially vary from what was observed on US-8.

\section{ACKNOWLEDGMENTS}

This study was supported by a Natural Sciences and Engineering Research Council grant to M. Filion.

\section{LITERATURE CITED}

Andreote, F. D., de Araújo, W. L., de Azevedo, J. L., van Elsas, J. D., da Rocha, U. N., and van Overbeek, L. S. 2009. Endophytic colonization of potato (Solanum tuberosum L.) by a novel bacterial endophyte, Pseudomonas putida strain $\mathrm{P} 9$, and its effect on associated bacterial communities. Appl. Environ. Microbiol. 75:3396-3406.

Arseneault, T., Goyer, C., and Filion, M. 2013. Phenazine production by Pseudomonas sp. LBUM223 contributes to the biological control of potato common scab. Phytopathology 103:995-1000.

Arseneault, T., Pieterse, C. M. J., Gérin-Ouellet, M., Goyer, C., and Filion, M. 2014. Long-term induction of defense gene expression in potato by Pseudomonas sp. LBUM223 and Streptomyces scabies. Phytopathology 104:926-932.

Axel, C., Zannini, E., Coffey, A., Guo, J., Waters, D. M., and Arendt, E. K. 2012. Ecofriendly control of potato late blight causative agent and the potential role of lactic acid bacteria: A review. Appl. Microbiol. Biotechnol. 96:37-48.

Bakker, P. A. H. M., Pieterse, C. M. J., and van Loon, L. C. 2007. Induced systemic resistance by fluorescent Pseudomonas spp. Phytopathology 97: 239-243.

Chin-A-Woeng, T. F. C., Bloemberg, G. V., van der Bij, A. J., van der Drift, K. M. G. M., Schripsema, J., Kroon, B., Scheffer, R. J., Keel, C., Bakker, P. A. H. M., Tichy, H.-V., de Bruijn, F. J., Thomas-Oates, J. E., and Lugtenberg, B. J. J. 1998. Biocontrol by phenazine-1-carboxamide-producing 
Pseudomonas chlororaphis PCL1391 of tomato root rot caused by Fusarium oxysporum f. sp. racidis-lycopersici. Mol. Plant-Microbe Interact. 11:10691077.

Chomczynski, P., Wilfinger, W., Kennedy, A., Rymaszewski, M., and Mackey, K. 2010. RNAzol® RT: A new single-step method for isolation of RNA. Nat. Methods 7:an4-an5.

Clément, J. A. J., Baldwin, T. K., Magalon, H., Glais, I., Gracianne, C., Andrivon, D., and Jacquot, E. 2013. Specific detection and quantification of virulent/ avirulent Phytophthora infestans isolates using a real-time PCR assay that targets polymorphisms of the Avr3a gene. Lett. Appl. Microbiol. 56:322-332.

Compant, S., Duffym, B., Nowak, J., Clément, C., and Barka, E. A. 2005. Use of plant growth-promoting bacteria for biocontrol of plant diseases: Principles, mechanisms of action, and future prospects. Appl. Environ. Microbiol. 71:4951-4959.

Daayf, F., Adam, L., and Fernando, W. G. D. 2003. Comparative screening of bacteria for biological control of potato late blight (strain US-8), using in-vitro, detached-leaves, and whole-plant testing systems. Can. J. Plant Pathol. 25:276-284.

Danies, G., Small, I. M., Myers, K., Childers, R., and Fry, W. E. 2013. Phenotypic characterization of recent clonal lineages of Phytophthora infestans in the United States. Plant Dis. 97:873-881.

de Boer, M., van der Sluis, I., van Loon, L. C., and Bakker, P. A. H. M. 1999. Combining fluorescent Pseudomonas spp. strains to enhance suppression of fusarium wilt of radish. Eur. J. Plant Pathol. 105:201-210.

DeCoste, N. J., Gadkar, V. J., and Filion, M. 2010. Verticillium dahlia alters Pseudomonas spp. populations and HCN gene expression in the rhizosphere of strawberry. Can. J. Microbiol. 56:906-915.

de Souza, J. T., de Boer, M., de Waard, P., van Beek, T. A., and Raaijmakers, J. M. 2003. Biochemical, genetic, and zoosporicidal properties of cyclic lipopeptide surfactants produced by Pseudomonas fluorescens. Appl. Environ. Microbiol. 69:7161-7172.

De Vrieze, M., Pandey, P., Bucheli, T. D., Varadarajan, A. R., Ahrens, C. H., Weisskopf, L., and Bailly, A. 2015. Volatile organic compounds from native potato-associated Pseudomonas as potential anti-oomycete agents. Front. Microbiol. 6:1295.

Duijff, B. J., Gianinazzi-Pearson, V., and Lemanceau, P. 1997. Involvement of the outer membrane lipopolysaccharides in the endophytic colonization of tomato roots by biocontrol Pseudomonas fluorescens strain WCS417r. New Phytol. 135:325-334.

Fry, W. E., Birch, P. R. J., Judelson, H. S., Grünwald, N. J., Danies, G., Everts, K. L., Gevens, A. J., Gugino, B. K., Johnson, D. A., Johnson, S. B., McGrath, M. T., Myers, K. L., Ristaino, J. B., Roberts, P. D., Secor, G., and Smart, C. D. 2015. Five reasons to consider Phytophthora infestans a reemerging pathogen. Phytopathology 105:966-981.

Goodwin, S. B., Smart, C. D., Sandrock, R. W., Deahl, K. L., Punja, Z. K., and Fry, W. E. 1998. Genetic change within populations of Phytophthora infestans in the United States and Canada during 1994 to 1996: Role of migration and recombination. Phytopathology 88:939-949.

Goodwin, S. B., Sujkowski, L. S., and Fry, W. E. 1996. Widespread distribution and probable origin of resistance to metalaxyl in clonal genotypes of Phytophthora infestans in the United States and Western Canada. Phytopathology 86:793-800.

Griffiths, R. I., Manefield, M., Whiteley, A. S., and Bailey, M. J. 2008. Section 1 update: DNA and RNA extraction from soil. Pages 2051-2060 in: Molecular Microbial Ecology Manual, Vol. 1. G. A. Kowalchuck, F. J. de Bruijn, I. M. Head, A. D. L. Akkermans, and J. D. van Elsas, eds. Springer, Dordrecht, The Netherlands.

Guyer, A., De Vrieze, M., Bönisch, D., Gloor, R., Musa, T., Bodenhausen, N., Bailly, A., and Weisskopf, L. 2015. The anti-Phytophthora effect of selected potato-associated Pseudomonas strains: From the laboratory to the field. Front. Microbiol. 6:1309.

Haverkort, A. J., Boonekamp, P. M., Hutten, R., Jacobsen, E., Lotz, L. A. P., Kessel, J. T., Visser, R. G. F., and van der Vossen, E. A. G. 2008. Societal costs of late blight in potato and prospects of durable resistance through cisgenic modification. Potato Res. 51:47-57.

Hultberg, M., Bengtsson, T., and Liljeroth, E. 2010. Late blight on potato is suppressed by the biosurfactant-producing strain Pseudomonas koreensis 2.74 and its biosurfactant. BioControl 55:543-550.
Hunziker, L., Bönisch, D., Groenhagen, U., Bailly, A., Schulz, S., and Weisskopf, L. 2015. Pseudomonas strains naturally associated with potato plants produce volatiles with high potential for inhibition of Phytophthora infestans. Appl. Environ. Microbiol. 81:821-830.

Hyo-Jeong, K., and Yong-Chull, J. 2006. Resistance induction and enhanced tuber protection by pre-inoculation with bacterial strains in potato plants against Phytophthora infestans. Mycobiology 34:67-72.

Kloepper, J. W., Schroth, M. N., and Miller, T. D. 1980. Effects on rhizosphere colonization by plant growth-promoting rhizobacteria on potato plant development and yield. Phytopathology 70:1078-1082.

Loper, J. E. 1988. Role of fluorescent siderophore production in biological control of Pythium ultimum by a Pseudomonas fluorescens strain. Phytopathology 78:166-172.

Maddula, V. S. R. K., Zhang, Z., Pierson, E. A., and Pierson, L. S., III. 2006. Quorum sensing and phenazines are involved in biofilm formation by Pseudomonas chlororaphis (aureofaciens) strain 30-84. Microb. Ecol. 52: 289-301.

Mazzola, M., Cook, R. J., Thomashow, L. S., Weller, D. M., and Pierson, L. S., III. 1992. Contribution of phenazine antibiotic biosynthesis to the ecological competence of fluorescent pseudomonads in soil habitats. Appl. Environ. Microbiol. 58:2616-2624.

Mazzola, M., Fujimoto, D. K., Thomashow, L. S., and Cook, R. J. 1995. Variation in sensitivity of Gaeumannomyces graminis to antibiotics produced by fluorescent Pseudomonas spp. and effect on biological control of take-all of wheat. Appl. Environ. Microbiol. 61:2554-2559.

Morrison, C. K., Novinscak, A., Gadkar, V. J., Joly, D. L., and Filion, M. 2016. Complete genome sequence of Pseudomonas fluorescens LBUM636, a strain with biocontrol capabilities against late blight of potato. Genome Announc. 4:e00446-16.

Ryals, J. A., Neuenschwander, U. H., Willits, M. G., Molina, A., Steiner, H.-Y., and Hunt, M. D. 1996. Systemic acquired resistance. Plant Cell 8: 1809-1819.

Saville, A., Graham, K., Grünwald, N. J., Myers, K., Fry, W. E., and Ristaino, J. B. 2015. Fungicide sensitivity of U.S. genotypes of Phytophthora infestans to six oomycete-targeted compounds. Plant Dis. 99:659-666.

Selin, C., Habibian, R., Poritsanos, N., Athukorala, S. N., Fernando, D., and de Kievit, T. R. 2010. Phenazines are not essential for Pseudomonas chlororaphis PA23 biocontrol of Sclerotinia sclerotiorum, but do play a role in biofilm formation. FEMS Microbiol. Ecol. 71:73-83.

Slininger, P. J., Schisler, D. A., Ericsson, L. D., Brandt, T. L., Frazier, M. J., Woodell, L. K., Olsen, N. L., and Kleinkopf, G. E. 2007. Biological control of post-harvest late blight of potatoes. Biocontrol Sci. Technol. 17:647-663.

St-Onge, R., Gadkar, V. J., Arseneault, T., Goyer, C., and Filion, M. 2011. The ability of Pseudomonas sp. LBUM223 to produce phenazine-1-carboxylic acid affects the growth of Streptomyces scabies, the expression of thaxtomin biosynthesis genes and the biological control potential against common scab of potato. FEMS Microbiol. Ecol. 75:173-183.

Thomashow, L. S., and Weller, D. M. 1988. Role of a phenazine antibiotic from Pseudomonas fluorescens in biological control of Gaeumannomyces graminis var. tritici. J. Bacteriol. 170:3499-3508.

Van Der Voort, M., Meijer, H. J. G., Schmidt, Y., Watrous, J., Dekkers, E., Mendes, R., Dorrestein, P. C., Gross, H., and Raaijmakers, J. M. 2015. Genome mining and metabolic profiling of the rhizosphere bacterium Pseudomonas sp. SH-C52 for antimicrobial compounds. Front. Microbiol. 6:693.

Wang, Y., Ohara, Y., Nakayashiki, H., Tosa, Y., and Mayama, S. 2005. Microarray analysis of the gene expression profile induced by the endophytic plant growth-promoting rhizobacteria, Pseudomonas fluorescens FPT9601-T5 in Arabidopsis. Mol. Plant-Microbe Interact. 18: 385-396.

Yan, Z., Reddy, M. S., Ryu, C.-M., McInroy, J. A., Wilson, M., and Kloepper, J. W. 2002. Induced systemic protection against tomato late blight by plant growth-promoting rhizobacteria. Phytopathology 92:1329-1333.

Zakharchenko, N. S., Kochetkov, V. V., Buryanov, Y. I., and Boronin, A. M. 2011. Effect of rhizosphere bacteria Pseudomonas aureofaciens on the resistance of micropropagated plants to phytopathogens. Appl. Biochem. Microbiol. 47:661-666. 